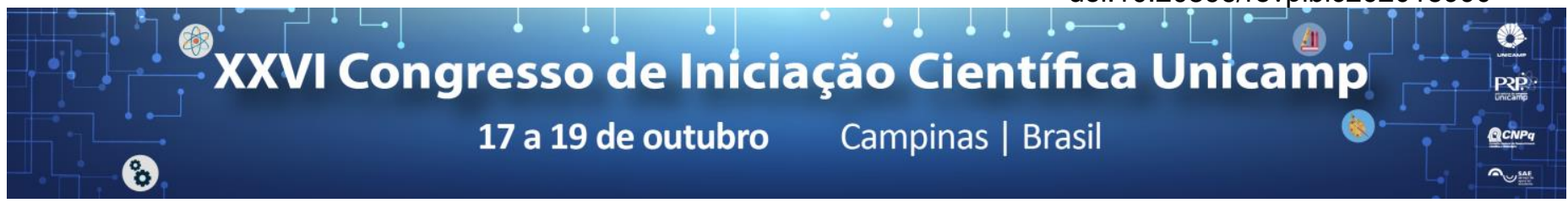

\title{
Método sensível e de baixo custo para análise de Selênio em alimentos: validação e aplicações
}

\author{
Mariana G. Moreira*, Eduardo A. Orlando, Juliana A. L. Pallone.
}

\section{Resumo}

A análise de selênio em alimentos pode ser realizada por diversas técnicas, entre elas a Espectrometria de Absorção atômica com gerador de hidretos, a qual se apresenta como uma técnica sensível e de baixo custo. Para tanto, é necessário um preparo prévio de amostras de alimentos, conhecido como processo de mineralização, em que há a decomposição da matéria orgânica com a liberação do elemento para o meio líquido, com o auxílio de ácidos e altas temperaturas. Para a análise de selênio, a mineralização foi realizada em placa de aquecimento e mufla. Com isso, um método foi desenvolvido, validado, com bons resultados, e aplicado para a análise de selênio em alimentos.

Palavras-chave: Espectrometria de Absorção Atômica, Gerador de Hidretos, Validação de Método.

\section{Introdução}

Atualmente, encontram-se na literatura alguns métodos para análise de selênio em matrizes complexas, como o uso de ICP-MS OU ICP-OES, principalmente, caracterizadas como técnicas de alto custo. Com isso, um método alternativo, de baixo custo, que envolve mineralização mista, com o uso de chapa de aquecimento, mufla e a espectrometria de absorção atômica com geração de hidretos (EAAGH), pode ser uma nova opção para aplicação em alimentos.

O selênio apresenta diversas funções benéficas no organismo humano, devido a sua atividade antioxidante, sendo a ingestão diária recomendada de $34 \mu \mathrm{g} / \mathrm{dia}$ para adultos ${ }^{1}$.

Recentemente, nosso grupo de pesquisa constatou potencial de minerais essenciais em bagaço de citrus, em que não foram encontrados dados sobre selênio nessa matriz em publicações científicas. Portanto, o objetivo do trabalho foi desenvolver, validar e aplicar um método sensível e de baixo custo para a avaliação de selênio em alimentos: castanha do Pará (Brasil), considerada fonte do mineral, e bagaço de citrus.

\section{Resultados e Discussão}

Foram utilizadas duas amostras de castanha do Pará (1 e 2) e 20 amostras de resíduos de citrus, cedidos pela indústria CP Kelco Headquarters, constituídas de cascas de laranjas e limões na forma seca, moída e homogeneizada, e castanhas disponíveis no comercio da cidade de Campinas, SP.

Para a mineralização das amostras foi utilizado um processo misto, como descrito pela Figura 1 abaixo.

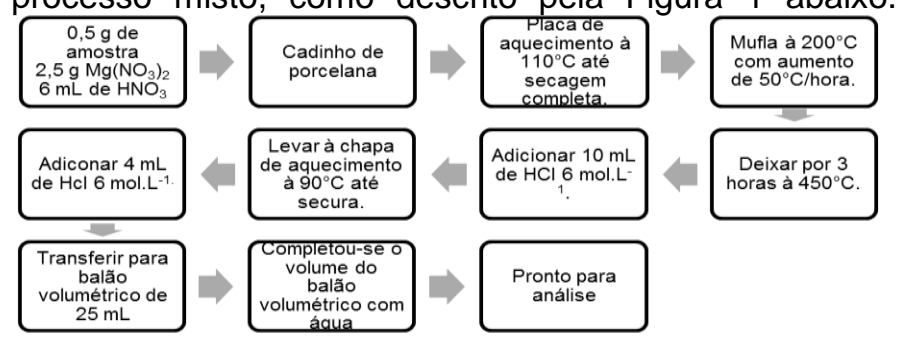

Figura 1. Fluxograma para mineralização das amostras
As condições para geração de hidretos-Se utilizadas foram: solução de boro-hidreto de sódio $\left(\mathrm{BH}_{4} \mathrm{Na}\right) 0,5 \%$ e hidróxido de sódio $(\mathrm{NaOH})$ 0,25\% e vazão de nitrogênio de aproximadamente $80 \mathrm{~mL} / \mathrm{mim}$.

Para a validação do método proposto, foram analisados parâmetros como linearidade da curva analítica, precisão, exatidão, limite de detecção (LD) e de quantificação (LQ), de acordo com o guia INMETRO $(2016)^{2}$ e todos os parâmetros se mostraram adequados, sendo os valores de LQ e LD de 26,5 e $9,2 \mu \mathrm{g} / \mathrm{kg}$, respectivamente.

A faixa de concentração estimada para $\mathrm{Se}$ em amostras de resíduos de citrus $(0,28-24,69 \mu \mathrm{g} / \mathrm{kg})$, ficou abaixo do limite de quantificação do método validado.

Os resultados para teor de Se em castanha do Pará encontram-se na Tabela 1 abaixo.

Tabela 1. Concentrações de selênio para as amostras de castanha do Pará.

\begin{tabular}{|c|c|c|c|}
\hline Amostra & $\begin{array}{c}\text { Concentração } \\
(\mathrm{mg} / 100 \mathrm{~kg})\end{array}$ & Faixa $(\mathrm{mg} / 100 \mathrm{~kg})$ & $\begin{array}{c}\mathrm{CV}(\%) \\
\text { médio }\end{array}$ \\
\hline Castanha 1 & 308,8 & $290,0-339,4$ & 8,7 \\
\hline Castanha 2 & 9070,2 & $8287,4-9770,5$ & 8,2 \\
\hline
\end{tabular}

$\mathrm{CV}=$ Coeficiente de Variação - análises em triplicatas.

Entre as amostras analisadas, observa-se que as amostras de castanhas apresentam altos valores de concentração de selênio, com variação de 290,0 até mais de $9000,0 \mathrm{mg} / 100 \mathrm{~kg}$, sendo que os valores encontrados correspondem aos valores da literatura ${ }^{3}$.

\section{Conclusões}

O método proposto se mostrou adequado, sensível e aplicável para a análise de selênio em diferentes matrizes. Os resultados encontram-se dentro do esperado, para as amostras de castanha do Pará, porém não possível encontrar concentrações significativas de selênio para as amostras de resíduos de citrus.

\section{Agradecimentos}

Ao PIBIC/CNPQ pela concessão de bolsa de iniciação científica.

\footnotetext{
${ }^{1}$ Agência Nacional de Vigilância Sanitária (ANVISA), Consulta Pública $n^{\circ} 80$ de 13 de dezembro de 2004. D.O.U de 17/12/2004

${ }^{2}$ DOQ-CGCRE-008 - Rev. 05 - Ago/16

${ }^{3}$ E.C. Silva Junior et al. / Chemosphere 188 (2017) 650e658
} 